\title{
Jurnal Dinamis
}

Vol. 9, No. 2, Bulan Tahun | 12-21

ISSN : 0216-7492, e-ISSN : 2809-3410

Homepage: https://talenta.usu.ac.id/dinamis

\section{PERANCANGAN DAN KONSTRUKSI INSTALASI AIR MINUM DARI KAPASITAS 500 LPS MENJADI 900 LPS DI PDAM TIRTANADI CEMARA}

\author{
Muhammad Taufik ${ }^{1 *}$, Alfian Hamsi ${ }^{2}$ \\ Departemen Teknik Mesin, Fakultas Teknik, Universitas Sumatera Utara \\ Jalan Dr. T. Mansyur No. 9, Padang Bulan, Kec. Medan Baru, Kota Medan, Sumatera Utara 20222, Indonesia \\ *Email: mtshrp@gmail.com
}

\begin{abstract}
ABSTRAK
Instalasi air minum adalah Jaringan atau sistem pendistribusian air minum dari sumber air melalui komponen penyalur dan penyambungnya untuk pemenuhan kebutuhan air dalam kehidupan sehari-hari. Perancangan ini dilakukan untuk penambahan kapasitas air minum di PDAM Tirtanadi Cemara dari 500 lps menjadi 900 lps dengan menggunakan perhitungan analitik metode Hazen William. Adapun parameter perancangannya yaitu diameter pipa outlet ke jaringan distribusi, kapasitas reservoir, dan kapasitas pompa yang digunakan. Pada hasil perhitungan didapatkan diameter Pipa outlet ke IPA Martubung adalah $\emptyset 0,8 \mathrm{~m}$, jalur Pancing $\emptyset 0,5 \mathrm{~m}$, dan jalur Karakatau $\quad \varnothing 0,5 \mathrm{~m}$. Untuk Kapasitas Reservoir yang dibutuhkan adalah $4536 \mathrm{~m}^{3}$ dengan diameter $16 \mathrm{~m}$ dan tinggi 12,5 m. Pada distribusi air minum ke IPA Martubung dibutuhkan 3 unit Pompa Booster dengan masing-masing kapasitas $300 \mathrm{KW}$, jalur pancing dibutuhkan 1 unit Pompa Booster dengan kapasitas $240 \mathrm{KW}$, dan jalur Karakatau dibutuhkan 1 unit Pompa Booster dengan kapasitas $225 \mathrm{KW}$, dan 1 unit Pompa Booster cadangan dengan kapasitas $240 \mathrm{KW}$. Hasil Simulasi menggunakan aplikasi Epanet berupa: Pressure dengan nilai maksimum $=1,37257952$ Bar, nilai minimum $=0$ Bar, dan Rata-rata $=0,836440156$ Bar. Velocity dengan nilai maksimum $=1,0 \mathrm{~m} / \mathrm{s}$, nilai minimum $=0 \mathrm{~m} / \mathrm{s}$, dan Rata-rata $=0,632926829 \mathrm{~m} / \mathrm{s}$. Headloss dengan nilai maksimum $=26,03 \mathrm{~m} / \mathrm{km}$, nilai minimum $=0 \mathrm{~m} / \mathrm{km}$, dan Rata-rata $=2,939268293 \mathrm{~m} / \mathrm{km}$.
\end{abstract}

Kata Kunci : Pipa, Reservoir, Pompa Booster.

\begin{abstract}
Drinking water installation is a network or system for distributing drinking water from water sources through its components and connectors to meet water needs in daily life. This design was carried out to increase the capacity of drinking water in PDAM Tirtanadi Cemara from 500 lps to 900 lps by using analytical calculations using the Hazen William method. The design parameters are the diameter of the outlet pipe to the distribution network, reservoir capacity, and the capacity of the pump used. The calculation results show that the diameter of the outlet pipe to the IPA Martubung is $\varnothing 0.8 \mathrm{~m}$, Pancing line is $\emptyset 0.5 \mathrm{~m}$, and Karakatau line is $\emptyset 0.5 \mathrm{~m}$. The required reservoir capacity is $4536 \mathrm{~m}^{3}$ with a diameter of $16 \mathrm{~m}$ and a height of $12.5 \mathrm{~m}$. In the distribution of drinking water to IPA Martubung, 3 units of Booster Pump are needed with a capacity of $300 \mathrm{KW}$, Pancing line requires 1 unit of Booster Pump with a capacity of $240 \mathrm{KW}$, and the Karakatau line requires 1 unit of Booster Pump with a capacity of $225 \mathrm{KW}$, and 1 unit Backup Booster Pump with of capacity $240 \mathrm{KW}$. Simulation results using the Epanet application is: Pressure with a maximum value $=1.37257952$ Bar, a minimum value $=0$ Bar, and an average $=0.836440156$ Bar. Velocity with maximum value $=1.0 \mathrm{~m} / \mathrm{s}$, minimum value $=0 \mathrm{~m} / \mathrm{s}$, and Average $=0.632926829 \mathrm{~m} / \mathrm{s}$. Headloss with maximum value $=26.03 \mathrm{~m} / \mathrm{km}$, minimum value $=0 \mathrm{~m} / \mathrm{km}$, and average $=2,939268293 \mathrm{~m} / \mathrm{km}$.
\end{abstract}

Keywords: Pipe, Reservoir, Booster Pump.

\section{PENDAHULUAN}

Air merupakan salah satu sumber daya alam yang memiliki fungsi sangat vital bagi kehidupan makhluk hidup yang ada di muka bumi. Untuk itu air perlu dilindungi agar dapat tetap bermanfaat bagi kehidupan manusia serta mahluk hidup lainnya. Tanpa adanya air maka kehidupan tidak akan dapat berlangsung. Kebutuhan akan penyediaan dan pelayanan air bersih dari waktu ke waktu semakin meningkat yang terkadang tidak diimbangi oleh kemampuan pelayanan. Peningkatan kebutuhan air tersebut jika tidak diimbangi dengan peningkatan jumlah produksi air bersih akan menimbulkan masalah dimana air bersih yang tersedia tidak akan cukup untuk memenuhi kebutuhan masyarakat pada wilayah tersebut. Hal ini dikarenakan masih kurangnya pelayanan pendistribusian air, sistem perpipaan yang kurang memadai, dan kapasitas reservoir yang masih kurang [1]. Perancangan instalasi air minum berkapasitas 900 lps di PDAM 
Tirtanadi Cemara ini bermaksud agar terpenuhinya jumlah konsumsi air pada masyarakat secara merata. Pada mulanya Instalasi Air Minum ini berkapasitas 500 lps di upgrade menjadi 900 lps di PDAM Tirtanadi Cemara. Konsep perancangan yang dipakai adalah rekonstruksi dengan berbagai pertimbangan struktural dan fungsional instalasi air minum.

Rumusan masalah dalam perancangan ini adalah mengenai skema instalasi jaringan pipa, perhitungan kapasitas reservoir, perhitungan daya pompa booster, perhitungan tekanan distribusi air minum, dan perhitungan velocity dan headloss pada jalur distribusi air minum.

Tujuan dari perancangan ini adalah untuk mendapatkan kapasitas air minum 900 lps di PDAM Tirtanadi Cemara serta memperoleh kinerja pompa booster yang efisien untuk proses distribusi air bersih di PDAM Tirtanadi Cemara.

\section{TEORI}

Instalasi Pendistribusian Air minum merupakan suatu sistem yang mengkombinasikan proses perpipaan, reservoir, dan pompa serta dilengkapi dengan pengontrolan proses juga instrument pengukuran yang dibutuhkan Instalasi ini harus didesain untuk menghasilkan cakupan air yang memadai untuk digunakan masyarakat bagaimanapun kondisi cuaca dan lingkungan. Selain itu, sistem dan subsistem dalam instalasi yang akan didesain harus sederhana, efektif, dapat diandalkan, tahan lama, dan murah dalam pembiayaan. Sistem distribusi air minum terdiri atas perpipaan, katup-katup, dan pompa yang membawa air yang telah diolah dari instalasi pengolahan menuju pemukiman, perkantoran dan industri yang mengkonsumsi air. Juga termasuk dalam sistem ini adalah fasilitas penampung air yang telah diolah (reservoir distribusi), yang digunakan saat kebutuhan air lebih besar dari suplai instalasi, meter air untuk menentukan banyak air yang digunakan, dan keran kebakaran [3]. Adapun analisis jaringan pipa menggunakan persamaan Hazern William sebagai berikut.

Kehilangan tekanan dalam pipa dihitung menggunakan persamaan 1 sebagai berikut.

$$
h_{f}=\frac{10,675 L \cdot Q^{1,852}}{C^{1,852} \cdot D^{4,87}}
$$

dengan:

$\mathrm{h}_{\mathrm{f}} \quad=$ kehilangan tekanan $(\mathrm{m})$

$\mathrm{L} \quad=$ panjang pipa $(\mathrm{m})$

$\mathrm{Q} \quad=\operatorname{debit}\left(\mathrm{m}^{3} / \mathrm{s}\right)$

C $\quad=$ koefisien Hazen William untuk pipa

$\mathrm{D}=$ diameter pipa $(\mathrm{m})$

Kecepatan aliran dihitung dengan menggunakan persamaan 2 sebagai berikut.

$$
\mathrm{v}=0,849 \cdot \mathrm{C} \cdot \mathrm{R}^{0,63} \cdot \mathrm{S}^{0,54}
$$

dengan:

$v \quad=$ kecepatan aliran $(\mathrm{m} / \mathrm{s})$

C $\quad=$ koefisien Hazen William untuk pipa

$R \quad=$ jari-jari pipa $(\mathrm{m})$

$S \quad=$ slope/kemiringan hidrolis

Debit aliran dihitung dengan persamaan 3 sebagai berikut.

$$
Q=0,27853 C \cdot D^{2,63} \cdot S^{0,54}
$$

dengan:

$Q \quad=$ debit air dalam pipa $\left(\mathrm{m}^{3} / \mathrm{s}\right)$

C = koefisien Hazen William untuk pipa

D = diameter pipa (m)

$S=$ slope/kemiringan hidrolis 
Kehilangan tekanan yang ekivalen dengan panjang pipa atau sebagai fungsi dari head kecepatan pada persamaan 4 berikut ini.

$$
\text { Panjang Ekuivalen Pipa }=\mathrm{K}_{1} \cdot \mathrm{d}
$$

Sedangkan head loss minor dihitung dengan persamaan 5 berikut ini.

$$
\mathrm{h}_{\mathrm{m}}=\mathrm{K}_{2} \frac{\mathrm{v}^{2}}{2 \cdot \mathrm{g}}
$$

dengan:

$K_{1}$ dan $_{2}=$ konstanta, dapat dilihat pada Lampiran C Tabel $K_{1}$ dan $K_{2}$ untuk kehilangan tekanan minor

D = diameter fitting $(\mathrm{m})$

$V \quad=$ kecepatan aliran $(\mathrm{m} / \mathrm{s})$

$g \quad=$ percepatan gravitasi, $\operatorname{dalam}\left(\mathrm{m} / \mathrm{s}^{2}\right)$

Total head pompa $(H)$ dihitung sesuai persamaan 6 sebagai berikut.

$$
\mathrm{H}=\mathrm{H}_{\mathrm{s}}+\mathrm{H}_{\mathrm{l}}+\mathrm{H}_{0}
$$

Untuk mencari Total head loss dihitung dengan persamaan berikut.

dengan :

$$
\mathrm{H}_{\mathrm{l}}=\mathrm{H}_{\mathrm{f}}+\mathrm{H}_{\mathrm{m}}
$$

$\mathrm{H}_{\mathrm{s}} \quad=$ total head statis $(\mathrm{m})$

$\mathrm{H}_{\mathrm{l}} \quad=$ total head loss $(\mathrm{m})$

$\mathrm{H}_{0} \quad$ = sisa tekanan

$\mathrm{H}_{\mathrm{f}} \quad$ = head loss mayor akibat friksi/gesekan

$\mathrm{H}_{\mathrm{m}} \quad=$ head loss minor akibat selain gesekan, antara lain akibat aksesoris

Daya pompa yang diperlukan dihitung dengan persamaan 7 sebagai berikut.

dengan :

$$
P=\frac{\text { Q.H. } \rho \cdot g}{1000}
$$

$$
\begin{array}{ll}
P & =\text { daya pompa }(\mathrm{KW}) \\
\rho & =\text { masa jenis air }\left(\mathrm{Kg} / \mathrm{m}^{3}\right) \\
g & =\text { percepatan gravitasi }\left(\mathrm{m} / \mathrm{s}^{2}\right) \\
Q & =\text { debit air }\left(\mathrm{m}^{3} / \mathrm{s}\right) \\
H & =\text { total head pompa }(\mathrm{m})
\end{array}
$$

Perkiraan efisiensi pompa berkisar antara 90\% sampai 95\%. Efisiensi motor 10\% lebih rendah dari efisiensi pompa [2-4].

\section{METODOLOGI PERANCANGAN}

Perancangan ini memerlukan beberapa data di lapangan untuk acuan dalam pembuatan gambaran dari skema instalasi. Metode pengambilan data pada perancangan ini sebagai berikut.

1) Observasi PDAM Tirtanadi Cemara untuk mengetahui kondisi dan instalasi distribusi air bersih pada unit tersebut.

2) Wawancara dengan operator pompa booster di PDAM Tirtanadi Cemara untuk menanyakan siklus kapasitas aliran air bersih.

3) Data spesifikasi pompa, ukuran pipa inlet dan otlet, serta ukuran reservoir di PDAM Tirtanadi Cemara.

4) Foto dokumentasi instalasi unit distribusi air bersih yaitu pipa distribusi, reservoir tank, dan pompa booster.

Dalam sistem penyediaan air bersih yang baik, diperlukan suatu pasokan air yang baik dan dalam jumlah yang cukup. Faktor kinerja (performance) suatu sistem jaringan air bersih juga penting untuk 
dipertimbangkan, karena dengan meninjau parameter-parameter kinerja serta faktor-faktor yang mempengaruhinya, maka dapat dilihat tingkat keberhasilan dari suatu kota/kawasan [5].

Tingkat keefektifan kineja dari tiap unit sistem distribusi seperti pompa booster, sistem aliran pipa, dan penampungan/reservoir akan sangat mempengaruhi keberhasilan suatu sistem jaringan distribusi air bersih. Adapun parameter yang dikaji pada perancangan ini sebagai berikut.

1) Pipa
a) Diameter pipa inlet dari Limau Manis adalah $800 \mathrm{~mm}$
b) Diameter pipa outlet ke IPA Martubung adalah $800 \mathrm{~mm}$
c) Diameter pipa outlet Jalur Pancing adalah $500 \mathrm{~mm}$
d) Diameter pipa outlet Jalur Karakatau adalah 500 mm

Jarak pipa air bersih yang akan di distribusikan sebagai berikut.
a) Jarak pipa outlet Cemara ke IPA Martubung adalah $12 \mathrm{KM}$
b) Jarak pipa outlet Cemara ke Jalur Pancing adalah 7 KM
c) Jarak pipa outlet Cemara ke Jalur Karakatau adalah 5 KM

2) Reservoir Tank

Reservoir yang di rancang dengan tipe ground storage reservoar. Reservoir pada PDAM Tirtanadi Cemara kapasitas 500 lps adalah $4000 \mathrm{~m}^{3}$.

3) Pompa Booster

Pompa booster yang digunakan pada kapasitas 500 lps di PDAM Tirtanadi Cemara sebanyak 3 unit dengan daya masing-masing $224 \mathrm{KW}$. Pompa tersebut bekerja dengan sistem kontrol PLC.

4) Valve dan Fitting

Berdasarkan data pada kapasitas 500 lps di PDAM Tirtanadi Cemara ada beberapa valve dan fitting yang digunakan diantaranya sebagai berikut.

Jumlah valve dan fitting ke IPA Martubung sebagai berikut.
a) Valve Butterfly = 8 Unit
b) Fitting elbow $45^{\circ} 2$ Piece $=5$ Unit
c) Fitting elbow $90^{\circ} 2$ Piece $=6$ Unit
d) Fitting elbow $90^{\circ} 3$ Piece $=7$ Unit
e) Fitting elbow $90^{\circ} 4$ Piece $=5$ Unit

Jumlah valve dan fitting Jalur Pancing sebagai berikut.
a) Valve Butterfly = 5 Unit
b) Fitting elbow $45^{\circ} 2$ Piece $=3$ Unit
c) Fitting elbow $90^{\circ} 2$ Piece $=3$ Unit
d) Fitting elbow $90^{\circ} 3$ Piece $=5$ Unit
e) Fitting elbow $90^{\circ} 4$ Piece $=4$ Unit

Jumlah valve dan fitting Jalur Karakatau sebagai berikut.
a) Valve Butterfly = 5 Unit
b) Fitting elbow $45^{\circ} 2$ Piece $=3$ Unit
c) Fitting elbow $90^{\circ} 2$ Piece $=3$ Unit
d) Fitting elbow $90^{\circ} 3$ Piece $=4$ Unit
e) Fitting elbow $90^{\circ} 4$ Piece $=3$ Unit

\section{HASIL DAN PEMBAHASAN}

Hasil dari perhitungan menggunakan persamaan metode Hazen William disajikan pada Tabel sebagai berikut ini.

\begin{tabular}{|c|c|c|c|c|}
\hline No. & Jalur Distribusi & Diameter Pipa (m) & $\begin{array}{c}\text { Jumlah Pompa } \\
\text { Booster (Unit) }\end{array}$ & $\begin{array}{c}\text { Daya Pompa } \\
\text { Booster (KW) }\end{array}$ \\
\hline 1 & IPA Martubung & 0,8 & 3 & $300 /$ unit \\
\hline
\end{tabular}




\begin{tabular}{|c|c|c|c|c|}
\hline 2 & Pancing & 0,5 & 1 & 240 \\
\hline 3 & Karakatau & 0,5 & 1 & 225 \\
\hline
\end{tabular}

Reservoir di desain dengan tipe ground storage reservoir. Untuk kapasitas efektif reservoir sebeagai berikut ini.

$$
\begin{aligned}
& \text { Kapasitas Reservoir }=10 \% \times Q_{\text {Max }} \text { day } \\
& \text { Kapasitas Reservoir }=10 \% \text { × }(0,9 \times 3600 \times 14) \\
& \text { Kapasitas Reservoir }=0,1 \times 45360 \\
& \text { Kapasitas Reservoir }=4536 \mathrm{~m}^{3}
\end{aligned}
$$

Simulasi yang dipakai untuk perhitungan distribusi air minum adalah Aplikasi Epanet. Skema simulasi yang dirancang ini merupakan jaringan distribusi air minum di PDAM Tirtanadi Cemara menuju IPA Martubung sesuai dengan topografi yang diambil dari google earth. Jumlah katup (valve) yang digunakan serta junction. Untuk data jarak pipa distribusi adalah 12000 meter, jumlah pompa booster sebanyak 3 unit, jumlah katup jenis PRV sebanyak 8 unit, dan 38 junction

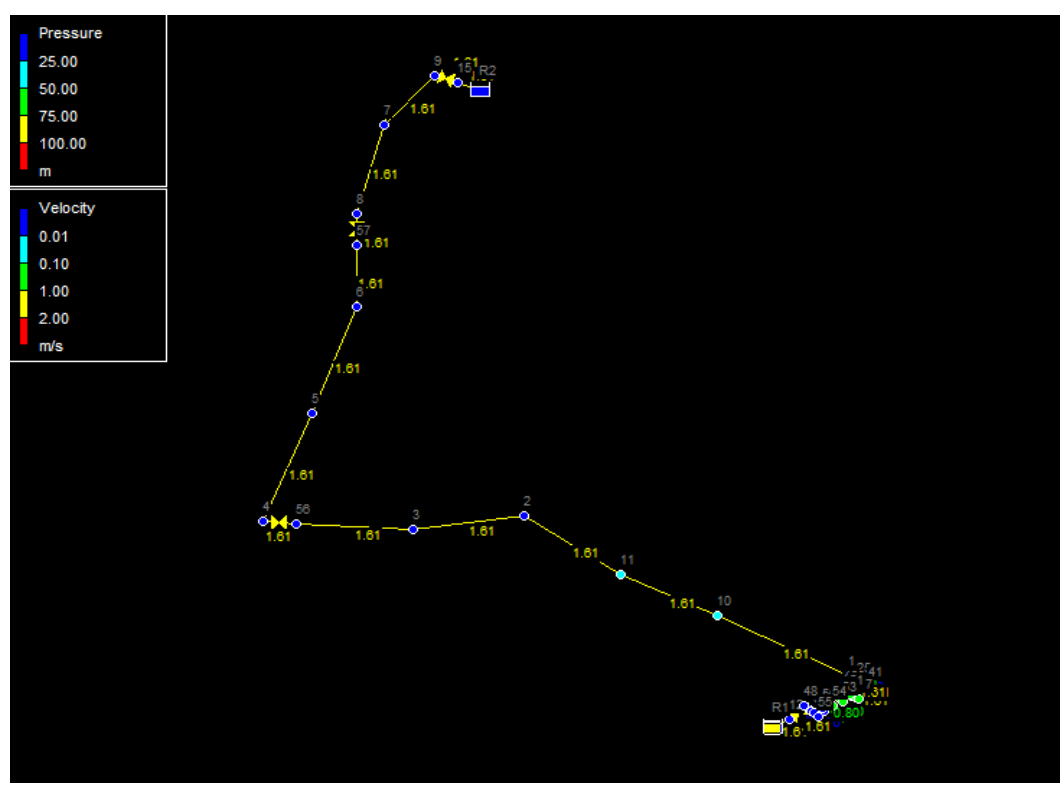

\section{Gambar Skema Simulasi Jaringan Distribusi Air minum di PDAM Tirtanadi Cemara menuju IPA Martubung}

Hasil dari pressure pada pipa distribusi air minum di PDAM Tirtanadi Cemara menuju IPA Martubung bervariasi dinominasi dari 40 data jaringan distribusi dimana nilai tekanannya sebagai berikut.

Maksimum : 1,37257952 Bar

Minimum : 0 Bar

Rata-rata : 0,836440156 Bar

Hasil dari velocity distribusi air minum di PDAM Tirtanadi Cemara menuju IPA Martubung bervariasi dinominasi dari 41 data jaringan distribusi dimana nilai velocitynya sebagai berikut.

Maksimum : $1,0 \mathrm{~m} / \mathrm{s}$

Minimum : $0 \mathrm{~m} / \mathrm{s}$

Rata-rata : 0,632926829 m/s

Hasil dari Headloss distribusi air minum di PDAM Tirtanadi Cemara menuju IPA Martubung bervariasi dinominasi dari 41 data jaringan distribusi dimana nilai Headlossnya sebagai berikut.

Maksimum : 26,03 m/km

Minimum : $0 \mathrm{~m} / \mathrm{km}$

Rata-rata : 2,939268293 m/km 


\section{KESIMPULAN}

1. Diameter Pipa Outlet yang dibutuhkan untuk kapasitas 900 lps pada distribusi air minum ke IPA Martubung adalah $\varnothing 0,8 \mathrm{~m}$, jalur Pancing $\varnothing 0,5 \mathrm{~m}$, dan jalur Karakatau $\varnothing 0,5 \mathrm{~m}$.

2. Volume Reservoir yang dibutuhkan untuk kapasitas air minum 900 lps di PDAM Tirtanadi Cemara adalah $4536 \mathrm{~m}^{3}$ dengan diameter $16 \mathrm{~m}$ dan tinggi 12,5 m.

3. Daya Pompa Booster yang dibutuhkan untuk distribusi air minum 900 lps di PDAM Tirtanadi Cemara ke IPA Martubung adalah 908,2 KW (3 Pompa = $300 \mathrm{KW})$, Jalur Pancing 239,2 KW (1 Pompa = 240 KW), Jalur Karakatau 225,2 KW (1 Pompa = 225 KW), dan 1 Pompa cadangan 240 KW. Maka total Pompa Booster yang dibutuhkan sebanyak 6 unit.

4. Hasil Simulasi menggunakan aplikasi Epanet berupa output Pressure, Velocity, dan Headloss pada Pipa Distribusi menuju IPA Martubung sebagai berikut.

a) Pressure dengan nilai maksimum = 1,37257952 Bar, nilai minimum $=0$ Bar, dan Rata-rata = 0,836440156 Bar.

b) Velocity dengan nilai maksimum $=1,0 \mathrm{~m} / \mathrm{s}$, nilai minimum $=0 \mathrm{~m} / \mathrm{s}$, dan Rata-rata $0,632926829 \mathrm{~m} / \mathrm{s}$.

c) Headloss dengan nilai maksimum $=26,03 \mathrm{~m} / \mathrm{km}$, nilai minimum $=0 \mathrm{~m} / \mathrm{km}$, dan Rata-rata = $2,939268293 \mathrm{~m} / \mathrm{km}$.

\section{DAFTAR PUSTAKA}

[1] Agustina, Dian Vitta. 2007. Analisa Kinerja Sistem Distribusi Air Bersih PDAM Kecamatan Banyumanik Di Perumnas Banyumanik (Studi Kasus Perumnas Banyumanik Kel. Srondol Watan). Tesis. Universitas Diponegoro Fakultas Manajemen dan Rekayasa Instrumen Jurusan Teknik Sipil

[2] Badan Standart Nasional Indonesia. Tata Cara Perencanaan Teknik Jaringan Distribusi dan Unit Pelayanan Sistem Penyediaan Air Minum. SNI 7509:2011

[3] Fuazen, Urai Iqbal, dan Eko Sarwono. 2019. Analisa Sistem Kinerja Booster Pump Si Sepakat 2 A. Yani Cabang PDAM Tirta Khatulistiwa, Jalan Imam Bonjol, Pontianak Selatan, Kota Pontianak, Kalimantan Barat. Jurnal Ilmiah. ISSN : 2579-4698

[4] Wahyudi, Ilham. 2013. Analisis Perancangan Pompa Guna Pemenuhan Kebutuhan Air Bersih PDAM Kota Probolinggo. Skripsi. Universitas Jember Fakultas Teknik Jurusan Teknik Mesin

[5] Gani, Fauzi A. 2018. Efek Penambahan Debit Kebutuhan pada Daerah Layanan Terrhadap Kondisi Existing Pipa Air Bersis Kota Langsa. Teras Jurnal. 8 (1) 